\title{
Industrial antifoam agents impair ethanol fermentation and induce stress responses in yeast cells
}

\author{
Jens Christian Nielsen ${ }^{1,2,3} \cdot$ Felipe Senne de Oliveira Lino ${ }^{1}$. \\ Thomas Gundelund Rasmussen ${ }^{1}$ - Jette Thykær ${ }^{2}$. Christopher T. Workman ${ }^{2}$. \\ Thiago Olitta Basso ${ }^{1,4}$
}

Received: 17 May 2017 / Revised: 6 September 2017 / Accepted: 17 September 2017 / Published online: 10 October 2017

(C) Springer-Verlag GmbH Germany 2017

\begin{abstract}
The Brazilian sugarcane industry constitutes one of the biggest and most efficient ethanol production processes in the world. Brazilian ethanol production utilizes a unique process, which includes cell recycling, acid wash, and nonaseptic conditions. Process characteristics, such as extensive $\mathrm{CO}_{2}$ generation, poor quality of raw materials, and frequent contaminations, all lead to excessive foam formation during fermentations, which is treated with antifoam agents (AFA). In this study, we have investigated the impact of industrial AFA treatments on the physiology and transcriptome of the industrial ethanol strain Saccharomyces cerevisiae CAT-1. The investigated AFA included industrially used AFA acquired from Brazilian ethanol plants and commercially available AFA commonly used in the fermentation literature. In batch fermentations, it was shown that industrial AFA compromised growth rates and glucose uptake rates, while commercial AFA had no effect in concentrations relevant for defoaming purposes. Industrial AFA were further tested in
\end{abstract}

Electronic supplementary material The online version of this article (https://doi.org/10.1007/s00253-017-8548-2) contains supplementary material, which is available to authorized users.

Christopher T. Workman

cwor@dtu.dk

Thiago Olitta Basso

thiagobasso@usp.br

1 Novozymes Latin America Ltda, 83707-660 Araucária, Brazil

2 Department of Biotechnology and Biomedicine, Technical University of Denmark, DK2800 Kgs. Lyngby, Denmark

3 Present address: Department of Biology and Biological Engineering, Chalmers University of Technology, SE412 96 Gothenburg, Sweden

4 Present address: Department of Chemical Engineering, Polytechnic School, University of São Paulo, 05508-010 São Paulo, Brazil laboratory scale simulations of the Brazilian ethanol production process and proved to decrease cell viability compared to the control, and the effects were intensified with increasing AFA concentrations and exposure time. Transcriptome analysis showed that AFA treatments induced additional stress responses in yeast cells compared to the control, shown by an up-regulation of stress-specific genes and a down-regulation of lipid biosynthesis, especially ergosterol. By documenting the detrimental effects associated with chemical AFA, we highlight the importance of developing innocuous systems for foam control in industrial fermentation processes.

Keywords Bioethanol $\cdot$ Antifoam $\cdot$ Fermentation . Sugarcane $\cdot$ Saccharomyces cerevisiae $\cdot$ Brazilian ethanol process

\section{Introduction}

Brazil has been at the frontline of the bioethanol industry since the 1970s and the sugarcane-based production process employed in Brazil constitute one of the most cost-efficient ethanologenic processes (Walker 2010). Having produced about 27 billion liters of ethanol in 2015, Brazil is the second largest ethanol producer in the world, only exceeded by the USA (Renewable Fuels Association 2016). The production process employed in Brazil is unlike other ethanol processes and includes yeast recycling, acid wash of the yeast biomass, and non-aseptic conditions, which altogether result in a continuously changing and highly stressful environment (DellaBianca et al. 2013). Despite this, the Brazilian bioethanol process shows a high efficiency with yields up to $93 \%$ of theoretic stoichiometric conversion (Amorim et al. 2011).

Foam formation is considered one of the main drawbacks of industrial fermentation processes, especially on 
large-scale processes, and Brazilian ethanol fermentations are no exception. Foam consists of gas bubble dispersions on liquid, solid/liquid, and solid systems (Eisner et al. 2007). A number of features greatly influence its occurrence in bioreactors, including medium composition, gas introduction/formation, and strain-specific characteristics of the production organism (Junker 2007). During ethanol fermentation by Saccharomyces cerevisiae strains, one of the main factors affecting foaming is the yeast itself. Foam stability is strongly influenced by the proteins adsorbing the gas/ liquid interface (Prins and Van Riet 1987), where mannoproteins from the yeast cell wall have shown to increase the foam stability to a great extent (Blasco et al. 2011). In the Brazilian ethanol setup, large volumes of biomass are used (about $10 \% \mathrm{w} \mathrm{v}^{-1}$ ), in a cell recycling system, and screening strategies have focused in selecting yeast with non-foaming phenotypes (Basso et al. 2008). However, since the process is non-sterile, the appearance of wild yeast strains with foaming phenotypes occurs regularly as contaminants resulting in increased foam formation. Having a yeast strain with a foaming phenotype is highly deleterious for the process economics, since a larger volume of the vessel is taken up by the foam, and it increases overall production costs, due to consumption of antifoam agents (AFA). This is especially important for production of low-value products such as ethanol (Basso et al. 2008).

Different chemical antifoams have different impacts on microbial physiology and cell growth (Routledge and Bill 2012), and the choice of the chemical used should take this into consideration. Several studies have considered the impact of AFA on cell physiology mainly as a result of the physicochemical effects on medium, such as reduction of the liquid surface tension, and decreased oxygen transfer rate (Morao et al. 1999; Garcia-Ochoa and Gomez 2009; Routledge et al. 2011). Still, some studies demonstrate a more direct impact on microbial physiology by the addition of AFA. One widely used AFA based on polypropylene glycol was shown to have toxic effects on Bacillus thuringiensis during sewage sludge fermentation for biopesticide production, by affecting the transport of nutrients and oxygen through the cell walls (Vidyarthi et al. 2000). Another AFA based on silicone polymers was shown to stimulate glycerol production, at the expense of ethanol, in $S$. cerevisiae steady-state chemostat cultures, under conditions of low oxygen and excess glucose (Grosz and Stephanopoulos 1990). These studies demonstrate that selection of AFA for a particular process, should take into consideration the physiological impact it might have on the microbial cell culture in a context dependent manner, rather than only the cost of the chemical.

This study has investigated the impact of AFA on the physiology and transcriptome of the industrial ethanol S. cerevisiae strain CAT-1. We show that while commercially available
AFA used in the yeast fermentation literature are innocuous at concentrations relevant for defoaming, industrial AFA used at Brazilian ethanol plants have severe negative impacts on the production performance of $S$. cerevisiae. Effects of AFA treatments were investigated in both defined and in molassesbased media, and transcriptome analysis suggested that alterations in lipid metabolism, as a consequence of AFA exposure, might account for a decreased stress tolerance in Brazilian ethanol fermentations.

\section{Materials and methods}

\section{Strain and media}

The industrial $S$. cerevisiae strain CAT-1 (CBMAI 0957, Coleção Brasileira de Microrganismos de Ambiente e Indústria) was used for all fermentation assays in this study. Single colonies were picked from plates and used for inoculation of precultures in yeast extract peptone dextrose (YPD) (containing $10 \mathrm{~g} \mathrm{l}^{-1}$ yeast extract, $20 \mathrm{~g} \mathrm{l}^{-1}$ peptone, and $20 \mathrm{~g}^{-1}$ glucose) or yeast nitrogen base (YNB) (BD Difco ${ }^{\mathrm{TM}}$ cat. no. 291940) media and incubated at $32{ }^{\circ} \mathrm{C}$ and $200 \mathrm{rpm}$ overnight. Sugarcane must was prepared by diluting sugarcane molasses in tap water to $20^{\circ} \mathrm{Brix}$, followed by centrifugation to remove solids. All media were autoclaved for sterilization. Water-soluble AFA were diluted in sterile demineralized water while water-insoluble AFA were diluted in $99 \%$ ethanol and added to the fermentation media. Ethanol was added to appropriate media to compensate for the ethanol contribution from ethanol-dissolved AFA. Industrial AFA samples (denoted as Ind_B and Ind_Z) are composed of two products, and they were used in all cultivations as a mixture of an antifoam product (AF_B and AF_Z, respectively) and a dispersant product (D_B and D_Z, respectively) at 1:1 proportion (Table 1).

\section{Batch fermentation}

All fermentations were inoculated from a preculture to an initial $\mathrm{OD}_{600}$ of 0.1 and incubated at $32{ }^{\circ} \mathrm{C}$. Small-scale fermentations were conducted in 96-well Costar flatbottom microtiter plates with a working volume of $100 \mu \mathrm{l}$ YPD medium and linear shaking on "fast" using a Biotek Synergy Mx plate reader (Winooski, VT, USA). Growth was monitored by measuring $\mathrm{OD}_{600}$ every $15 \mathrm{~min}$. Shake flask fermentations were conducted in 500-ml Erlenmeyer flasks in YNB medium, with $200 \mathrm{rpm}$ orbital shaking and samples for biomass and metabolite quantification were collected every $1.5 \mathrm{~h}$. All fermentations were conducted in biological triplicates. 
Table 1 Commercial and industrial antifoam agents (AFA) used in this study

\begin{tabular}{clll}
\hline Product & Fraction & Active ingredient(s) & Source \\
\hline Antifoam 204 & Single & Polypropylene-based polyether dispersion & $\begin{array}{c}\text { Commercial sample } \\
\text { (Sigma-Aldrich, St. Louis, MO, USA) } \\
\text { Commercial sample } \\
\text { (Sigma-Aldrich, St. Louis, MO, USA) } \\
\text { Commercial sample } \\
\text { (Sigma-Aldrich, St. Louis, MO, USA) } \\
\text { P2000 }\end{array}$ Single \\
Ind_B & Single & Aqueous emulsion with 30\% silicone & $\begin{array}{c}\text { Industrial sample } \\
\text { (Aratrop Industrial, São Paulo, Brazil) }\end{array}$ \\
Ind_Z & Antifoam AF_B & Polypropylene glycols & $\begin{array}{c}\text { Industrial sample } \\
\text { (Alcolina, São Paulo, Brazil) }\end{array}$ \\
\hline
\end{tabular}

Single: product is composed of one single fraction

$A F \_B$ antifoam fraction of product Ind_B, $D \_B$ dispersant fraction of product Ind_B, $A F \_Z$ antifoam fraction of product Ind $Z, D \_Z$ dispersant fraction of product Ind_Z

\section{Yeast propagation and fed-batch fermentation with cell recycling}

To propagate sufficient yeast biomass for inoculation of molasses fermentations, a YPD preculture was incubated overnight at $32{ }^{\circ} \mathrm{C}$ without shaking. YPD cultures were subsequently fed in discrete portions with propagation medium (sugarcane must diluted to $10^{\circ}$ Brix and enriched with yeast extract $\left(5 \mathrm{~g}^{-1}\right)$ and peptone $\left.\left(10 \mathrm{~g}^{-1}\right)\right)$ to a final volume of 21 during the course of 3 days.

Fed-batch fermentations representing the typical industrial process were carried out in 50-ml falcon tubes. In the first cycle, cells from the propagation culture were added to each tube in an amount corresponding to $8 \%\left(\mathrm{w} \mathrm{v}^{-1}\right)$ of the final volume. Cells were fed with $25 \mathrm{ml}$ sugarcane must in three equal-sized portions with $1.5 \mathrm{~h}$ intervals. Cultures were incubated for $7 \mathrm{~h}$ at $32{ }^{\circ} \mathrm{C}$ without agitation and left at room temperature overnight. In the following day, cells were separated from the fermentation wine by centrifugation (3220 rcf, $5 \mathrm{~min})$ and resuspended in wine $\left(30 \%\right.$ wet weight $\left.\mathrm{w} \mathrm{w}^{-1}\right)$ to simulate the industrial centrifuge efficiency. Cells were further diluted in demineralized water (1:1) before addition of $1 \mathrm{M}$ sulphuric acid to a final $\mathrm{pH}$ of 2.5. After incubation in acid at room temperature for $1 \mathrm{~h}$, feeding of sugarcane must was initiated, restarting the process. Industrial AFA were administered as in the industry, with the dispersant added during the acid wash and antifoam after $1 \mathrm{~h}$ of fermentation.

Metabolite concentrations in the fermentation wine were determined with high-performance liquid chromatography (HPLC) and biomass as wet weight. Moreover, $\mathrm{CO}_{2}$ formation was followed during the fermentation by measuring the weight loss of the fermentation tubes and assuming all loss of weight could be attributed to $\mathrm{CO}_{2}$ production. Yields were calculated on a $\mathrm{C}$-mole basis relative to total reducing sugars, i.e., sucrose, glucose, and fructose. The wine returned, and hence the addition of extracellular metabolites from the previous fermentation, was taken into account and corrected for in the yield calculations.

\section{Metabolite quantification}

Metabolite concentrations were determined by highperformance liquid chromatography (HLPC). Sugars (sucrose, glucose, and fructose) were separated on an Aminex HPX-87H ion-exclusion column (Hercules, CA, USA), isocratically eluted at $25^{\circ} \mathrm{C}$ with $5 \mathrm{mM} \mathrm{H}_{2} \mathrm{SO}_{4}$ as the mobile phase at a flow rate of $0.6 \mathrm{ml} \mathrm{min}^{-1}$. Glycerol, ethanol, and organic acids were determined similarly, but with a higher flow rate $\left(0.7 \mathrm{ml} \mathrm{min}^{-1}\right)$ and temperature $\left(65^{\circ} \mathrm{C}\right)$. Detection was performed refractrometrically. For the sugarcane fermentations, ethanol was measured by distillation of $10 \mathrm{ml}$ fermentation wine and subsequent density determination using an Anton Paar electronic density meter (Graz, Austria) (Basso et al. 2008).

\section{Determination of cell viability}

Samples from sugarcane fermentations were diluted 1000 times in demineralized water to a final concentration of ap-

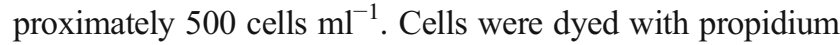
iodide (PI) $\left(215 \mathrm{nmol} \mathrm{ml}^{-1}\right)$ and incubated for 5-10 $\mathrm{min}$ in the dark before applying the samlpes on a flow cytometer Accuri C6 (BD, Franklin Lakes, NJ, USA) according to the manufacturer's recommendations. Threshold of FSC-H gate was set to 200,000 to avoid large particles. Quantification of viability was done by separating two populations generated from the histogram of the PI fluorophore detector FL3-H.

\section{RNA extraction, sequencing, and quantification}

Samples for transcriptome analysis were collected from cycle 5 of the sugarcane fermentations, after $4 \mathrm{~h}$ of incubation, spun down, resuspended in RNAlater (Qiagen, Hilden, Germany, 
cat. no. 76106) and incubated for $1 \mathrm{~h}$, at $4{ }^{\circ} \mathrm{C}$. Subsequently, cells were pelleted and stored at $-80^{\circ} \mathrm{C}$ until further analysis. Biomass samples were lysed on a FastPrep instrument (Lysing Matrix Y from MP Biomedicals, Hampton, NH, USA, cat. no. 116960050) and total RNA extracted according to the manufacturer's recommendations (TRIzol Plus RNA purification kit, Invitrogen, Carlsbad, CA, USA, cat. no. 12183-555). cDNA libraries were prepared using Illumina TruSeq kit (Illumina, San Diego, CA, USA, cat. no. RS-122-2001) with enzymatic rRNA depletion. Sequencing was done using Illumina HiSeq 2000 technology yielding an average of $26 \mathrm{M}, 99$-nt long paired-ends reads per sample, with an average insert distance of $300 \mathrm{nt}$ 's. Reads in fastq format were quality assessed using FastQC (v0.10.1) (Andrews 2012) and trimmed according to varying GC-content at the $5^{\prime}$ and $3^{\prime}$ ends, and a quality cut-off $(Q<20)$. Trimmed sequence reads were mapped to the $S$. cerevisiae s288C reference genome (version EF4, Ensembl) (Engel et al. 2014) using Tophat (v2.0.9) (Kim et al. 2013), and transcripts were quantified on a count basis using HTSeq (v0.6.0) (Anders et al. 2015) with "intersection-strict" mode for overlapping reads. Data normalization and calculation of gene level statistics were conducted using the R package DESeq2 (Love et al. 2014), and significantly differentially expressed genes were identified as having Benjamini-Hochberg-corrected $p$ values less than 0.01 . Transcripts with overall counts less than 15 among all samples were removed for the further analysis. The transcriptome data discussed in this publication have been deposited in NCBI's Gene Expression Omnibus and are accessible through the GEO Series accession number GSE103004.

\section{Gene-set analysis}

Gene sets with amiGO gene ontology (GO) terms were downloaded from Ensembl (Yates et al. 2016), and genemetabolite associations for reporter metabolite analysis were extracted from the yeast 7 genome-scale metabolic model (Aung et al. 2013). Gene set analysis was performed with the normalized transcript counts using the $\mathrm{R}$ package Piano (Varemo et al. 2013), and gene sets with Benjamini-Hochberg corrected $p$-values less than 0.01 were considered significant.

\section{Linear models}

Linear models were applied to test whether mRNA levels were a linear function of cell viability. Modeling was performed using the R implementation of an ANOVA $F$ test with $p<0.01$ as criterium to reject the null-hypothesis, i.e., that gene expression and viability were uncorrelated. Enrichment of GO terms among genes with significant positive or negative correlations was tested with all expressed transcripts as background, using the hypergeometric test implemented in amiGO (Carbon et al. 2009).

\section{Results}

\section{The differential effects of commercial and industrial antifoam agents on yeast physiology under defined laboratory conditions}

In this study, a total of seven AFA were utilized and a description of each is provided in Table 1. Three commercial AFA were selected as commonly used in the fermentation literature for yeast physiological studies (Brochado et al. 2010; Routledge et al. 2011; Basso et al. 2011), while four industrial AFA were acquired as samples from two Brazilian ethanol plants and are currently being used in the Brazilian ethanol industry. As two AFA are used in conjunction to control foam in the industrial process (Basso et al. 2008; Della-Bianca et al. 2013), the four industrial AFA represent two combination treatments for defoaming (Ind_B and Ind_Z). These combination treatments consist of one dispersant (D_B or D_Z) which is added into the yeast slurry prior feeding, to prevent foam formation, and an antifoam (AF_B or AF_Z) which is added when foam formation occurs during fermentation (Supplementary Fig. S1).

A physiological characterization of the industrial yeast S. cerevisiae strain CAT-1 was performed initially in a microplate reader setup, in order to assess the effect of the AFA on growth rate at different concentrations. Secondly, a more detailed investigation was done using shake-flask batch cultivations in defined medium (YNB) to study the impact of industrial AFA on major physiological parameters, such as product yields.

Microplate cultivations in YPD medium with $10 \mathrm{~g}^{-1}$ glucose were used to estimate the effect of different concentrations of AFA on the maximum specific growth rate $\left(\mu_{\max }\right)$. In the case of commercial AFA, concentrations up to 100 times the manufacturer's recommendation were tested. The presence of Antifoam C and P2000 decreased growth rates as compared to the control (no AFA added) in concentrations of 750 and $7500 \mathrm{mg} \mathrm{l}^{-1}$, respectively, while Antifoam 204 displayed no effect on growth rate up to $375 \mathrm{mg} \mathrm{l}^{-1}$ (Fig. 1a) (higher concentrations of Antifoam 204 did not emulsify and hence were not tested). Assessing the industrial AFA revealed that both treatments start to reduce growth rate at $60 \mathrm{mg} \mathrm{l}^{-1}$ (Fig. 1b), which corresponds to the average concentration used in the industrial setting (Pecege-Esalq 2012). To further investigate how metabolite production and growth characteristics were influenced by the two industrial AFA, shake-flask cultivations were carried out in YNB 

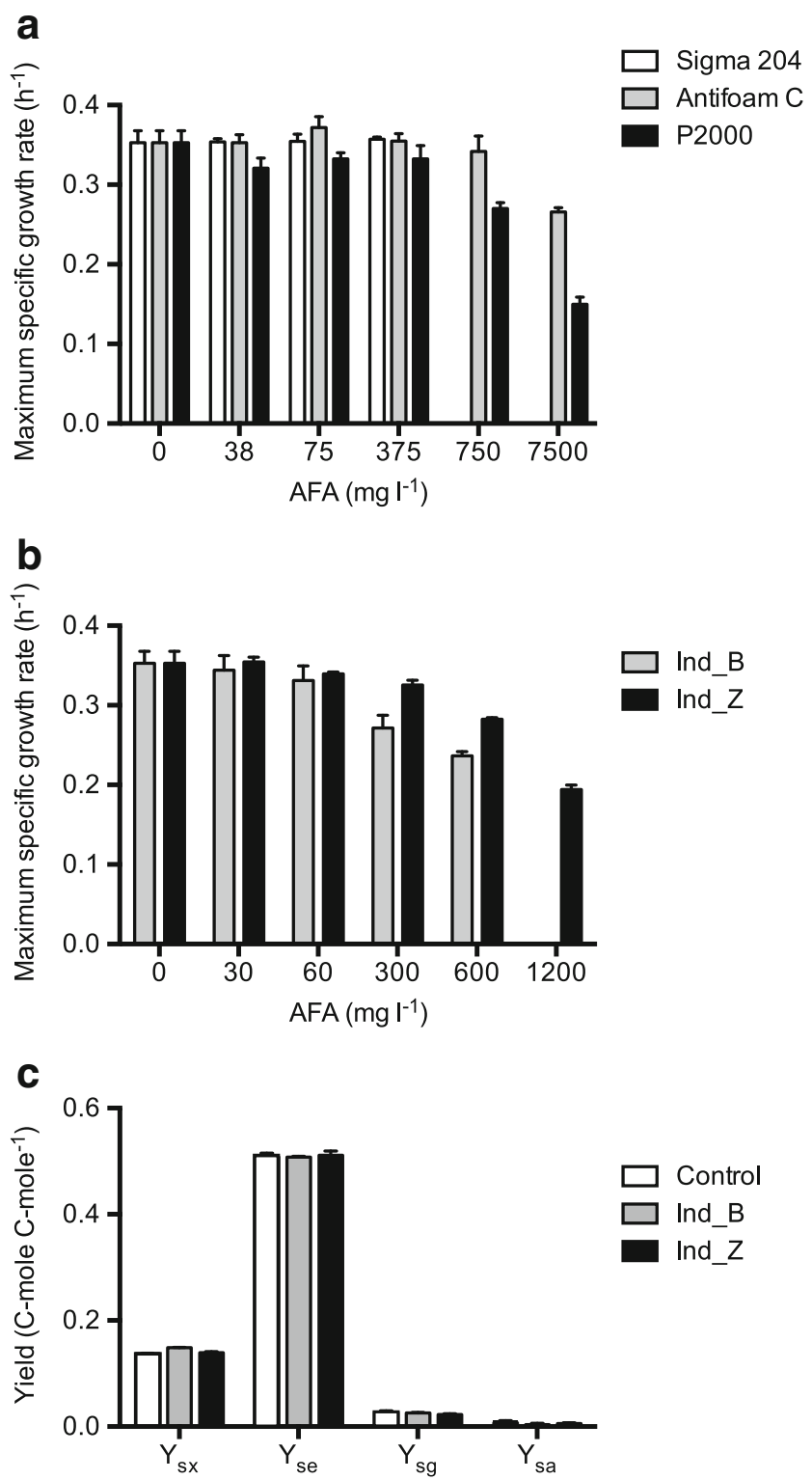

Fig. 1 The effect of commercial and industrial AFA on growth rate and product yields of $S$. cerevisiae CAT-1 cultures. a Maximum specific growth rate $\left(\mathrm{h}^{-1}\right)$ in YPD medium in microplate reader cultures in the presence of different concentrations of three commercial AFA samples. b Maximum specific growth rate $\left(\mathrm{h}^{-1}\right)$ in YPD medium in microplate reader cultures in the presence of different concentrations of two industrial AFA samples (products Ind B and Ind Z are composed of an antifoam and a dispersant, at equal amounts). c Product yields during growth of S. cerevisiae CAT-1 in shake-flask cultures on YNB with $10 \mathrm{~g} \mathrm{l}^{-1}$ glucose as sole carbon source, in the presence of AFA Ind B (30 $\mathrm{mg}^{-1}$ AF B and $\left.30 \mathrm{mg} \mathrm{l}^{-1} \mathrm{D} \_\mathrm{B}\right)$ and Ind $\mathrm{Z}\left(30 \mathrm{mg} \mathrm{l}^{-1} \mathrm{AF} \mathrm{Z}^{-}\right.$and $\left.30 \mathrm{mg} \mathrm{l}^{-1} \mathrm{D} \_\bar{Z}\right)$. Yield on biomass $\left(Y_{\mathrm{sx}}\right)$, on ethanol $\left(Y_{\mathrm{se}}\right)$, on glycerol $\left(Y_{\mathrm{sg}}\right)$ and on acetate $\left(Y_{\mathrm{sa}}\right)$. Values represent the average of triplicate experiments \pm standard deviations

containing $10 \mathrm{~g}^{-1}$ glucose. Under these conditions, while yield coefficients virtually remained unchanged by the presence of industrial AFA, specific metabolite production and consumption rates were negatively affected in view of the reduced growth rates (Fig. 1c).
Industrial AFA impair cell viability and fermentation kinetics at molasses-based fermentation with cell recycle

After this initial evaluation, the influence of industrial AFA on the fermentation performance of $S$. cerevisiae was investigated at the physiological and at the transcriptional levels, in a setup that mimicked as far as possible the industrial ethanol process employed in Brazil. The two industrial defoaming treatments currently used in the Brazilian bioethanol industry (Ind_B and Ind_Z) were assessed and benchmarked against a control experiment without the addition of AFA (Table 1). The fermentations were conducted as laboratory-scale replications of the industrial production process, as described elsewhere (Basso et al. 2014; Raghavendran et al. 2017) (Supplementary Fig. S1). In brief, this included yeast cell recycle, acid wash, and fedbatch cultivations in sugarcane must for five consecutive fermentation cycles. For all fermentations, the loss of $\mathrm{CO}_{2}$ was monitored continuously and fermentation yields were determined. The two components of the industrial defoaming treatments were added separately as done in industry, with dispersants (D_B or D_Z) added during the acid wash, while antifoams (AF_B or AF_Z) were added after $1 \mathrm{~h}$ of fermentation, where foam issues are more prominent in industrial fermentations (H.V. Amorim, pers. comm.).

When simulating the industrial fermentation conditions, the overall fermentation yields on ethanol, $\mathrm{CO}_{2}$, glycerol, and acetate showed no significant differences among the treatments. Likewise, residual sugar levels were quite similar among conditions (Table 2). The biomass gain along the cultivation cycles was virtually absent (data not shown), which is in agreement with observations under industrial conditions, especially when a molasses-based must is used (Amorim et al. 2011). The carbon balance for all fermentations reached $87-90 \%$ of the total carbon input; however, the missing carbon can be attributed to ethanol evaporation and an underestimation of the $\mathrm{CO}_{2}$ formation, since $\mathrm{CO}_{2}$ loss was estimated by weighing the flasks, and could not be properly monitored during feeding and antifoam addition periods.

In the first cycles, both industrial AFA treatments (Ind B and Ind $\mathrm{Z}$ ) showed cumulative $\mathrm{CO}_{2}$ production levels comparable to the control, although a reduction was observed in the later cycles (cycle 4 and cycle 5). Treatment Ind Z imposed the greatest $\mathrm{CO}_{2}$ reduction, showing cumulative production levels corresponding to $52 \%$ of the control, while Ind B treated cells were producing $77 \%$ of the $\mathrm{CO}_{2}$ in the control (Fig. 2a). The $\mathrm{CO}_{2}$ evolution over time showed that the $\mathrm{CO}_{2}$ reduction was mainly apparent in the beginning of the fermentations where an increased lag phase was observed for the AFA treatments (Fig. 2b). Ethanol was not quantified during fermentations (only at the end of each cycle), but it can be assumed that the $\mathrm{CO}_{2}$ formation has a 1:1 stoichiometry to ethanol production. Based on this assumption, ethanol 
Table 2 Physiological parameters during yeast fed-batch fermentation of sugarcane must. Yield coefficients and residual sugars in the $5^{\text {th }}$ fermentation cycle of a fed-batch culture of strain S. cerevisiae CAT-1 with no AFA added (control) and with the addition of two industrial AFA (Ind B and Ind Z). All yields were calculated based on total consumed sugars (sucrose, glucose, and fructose)

\begin{tabular}{|c|c|c|c|c|c|c|}
\hline Condition & $\begin{array}{l}\text { Ethanol yield } \\
\left(\mathrm{C}-\mathrm{mol} \mathrm{C}-\mathrm{mol}^{-1}\right)\end{array}$ & $\begin{array}{l}\mathrm{CO}_{2} \text { yield } \\
\left(\mathrm{C}-\mathrm{mol} \mathrm{C}-\mathrm{mol}^{-1}\right)\end{array}$ & $\begin{array}{l}\text { Glycerol yield } \\
\left(\mathrm{C}-\mathrm{mol} \mathrm{C}-\mathrm{mol}^{-1}\right)\end{array}$ & $\begin{array}{l}\text { Acetate yield } \\
\left(\mathrm{C}-\mathrm{mol} \mathrm{C}-\mathrm{mol}^{-1}\right)\end{array}$ & Residual sugars $\left(\mathrm{g} \mathrm{l}^{-1}\right)$ & C-balance* \\
\hline Control & $0.577 \pm 0.005$ & $0.289 \pm 0.003$ & $0.003 \pm 0.000$ & $0.001 \pm 0.000$ & $5.48 \pm 0.05$ & $0.870 \pm 0.007$ \\
\hline Ind_B & $0.593 \pm 0.006$ & $0.297 \pm 0.003$ & $0.002 \pm 0.000$ & $0.001 \pm 0.000$ & $6.16 \pm 0.72$ & $0.894 \pm 0.009$ \\
\hline Ind_Z & $0.584 \pm 0.002$ & $0.292 \pm 0.001$ & $0.003 \pm 0.000$ & $0.001 \pm 0.000$ & $5.84 \pm 0.26$ & $0.881 \pm 0.003$ \\
\hline
\end{tabular}

Values represent the average \pm standard deviation from triplicate experiments

*Carbon balance was calculated as the sum of all yield coefficients

productivity was reduced in the same proportion as the $\mathrm{CO}_{2}$ levels, and hence resulted in a reduced ethanol yield after $7 \mathrm{~h}$ of fermentation (in the industrial process, the fermentations are typically terminated after $7-9 \mathrm{~h}$ ). The final $\mathrm{CO}_{2}$ emission (after $\sim 24 \mathrm{~h}$ ) reached the same level for all treatments emphasizing that the total yield is not affected.

For all treatments, the viability declined for each fermentation cycle as expected (Basso et al. 2008), highlighting the stressful nature of the process (Fig. 2c). The viability profile showed a similar pattern as the $\mathrm{CO}_{2}$ emission, with the industrial AFA treatments reducing viability compared to the control. Viability results explain the underlying reason for the observed reduction in $\mathrm{CO}_{2}$ levels, as fewer living cells were present to produce $\mathrm{CO}_{2}$. This trend of reduced viability was consistent for all industrial AFA treatment experiments performed and moreover, proved to be concentration dependent (data not shown).

\section{Transcriptome analysis reveals that AFA induce additional stress responses in yeast cells during industrial conditions}

In order to better understand the physiological perturbations caused by the AFA treatments, samples were collected for transcriptome analysis $4 \mathrm{~h}$ after initiation of the last fermentation cycle (cycle 5), which was $1 \mathrm{~h}$ after the feeding had ended. RNA sequencing was performed using an Illumina HiSeq instrument with the paired-end method. Considering that the quality of the published genome assembly of the strain CAT-1 was not suitable as a reference for read mapping (Babrzadeh et al. 2012), reads were aligned to the genome of the laboratory strain S. cerevisiae S288C. For each sample, an average of $78.3 \% \pm 2.1$ of the sequencing reads were successfully mapped to the reference genome. The relatively low mapping frequency was anticipated due to the distant relation between CAT-1 and the reference strain S288C (Babrzadeh et al. 2012). Reads mapping to open reading frames in S288C were quantified, and a total of 6357 transcripts were identified as being expressed in at least one of the samples. Quality and reproducibility of the RNA-seq samples were assessed by a pairwise comparison of transcript levels for each replicate and showed a Pearson correlation coefficient of at least 0.94 between all samples (Supplementary Fig. S2).

To assess the global effects of the treatments on gene expression, a principal component analysis (PCA) was conducted based on all measured transcript levels (Fig. 3a and Supplementary Fig. S3). The PCA showed that the replicates of each treatment clustered together as expected, except for one of the control treatments which was deviating on the first PC, although was comparable on the second PC. All samples were included in the analysis since the results proved to be similar to excluding the deviating control sample. The relative effects of the treatments were in agreement with the observed physiological changes with the Ind_B treatment resulting in only minor changes, while the Ind_ $\mathrm{Z}$ treated cells showed more drastic changes in expression levels, as seen by its relative distance to the control in the first two PC dimensions. A differential expression analysis further confirmed the relative pertubations caused by the AFA treatments as a total of 297 genes in Ind_B and 439 genes in Ind_Z were significantly differentially expressed relative to the control (adjusted $p$ value $<0.01$ ). Among these genes, a total of 69 were upregulated and 42 were down-regulated in both species (Fig. 3).

To identify the most apparent transcriptional responses to the AFA treatments and to group the affected genes based on function, gene set analysis was conducted with the normalized transcript counts for each treatment in comparison to the untreated cells (Supplementary Data 1). Gene sets included gene ontology (GO) terms and metabolites connected to genes through the corresponding enzymatic reaction and identified using the reporter feature algorithm (Patil and Nielsen 2005). In addition to these analyses, linear models were applied between the gene expression of each gene in a sample relative to the cell viability observed in the sample, in order to identify gene expression patterns that could be explained by the physiological response. The main transcriptional responses identified are summarized in Fig. 4.

The most significantly enriched GO term among the upregulated genes in Ind_B was transmembrane transport (GO:0055085), and some of these transporters were related 

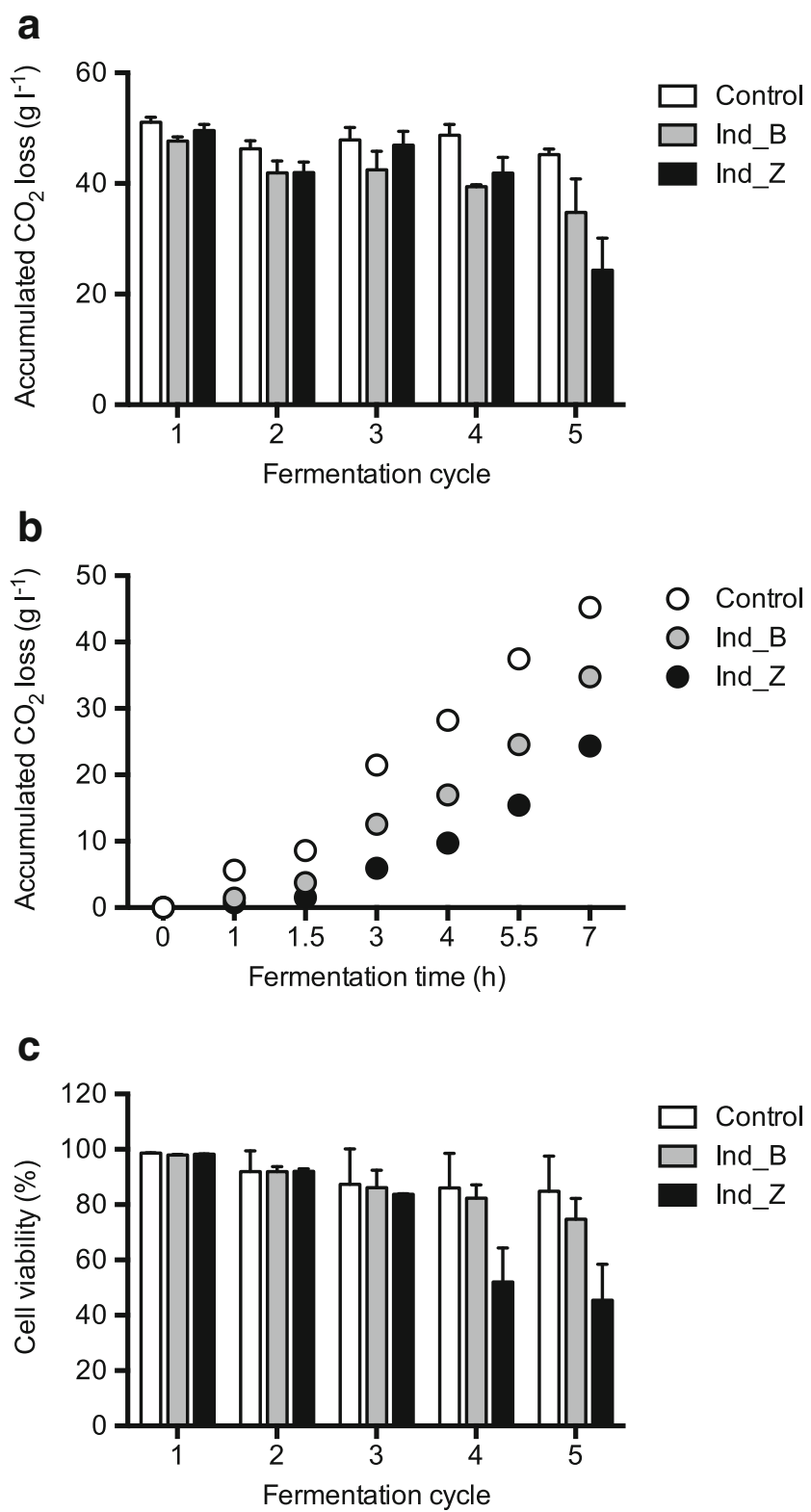

Fig. 2 The influence of industrial AFA on S. cerevisae CAT-1 fed-batch fermentation of sugarcane must. a Accumulated $\mathrm{CO}_{2}$ loss (in $\mathrm{g}^{-1}$ ) over five fermentation cycles, $\mathbf{b}$ Accumulated $\mathrm{CO}_{2}$ loss (in $\mathrm{g}^{-1}$ ) in the course of the 5th cycle, and $\mathbf{c}$ yeast viability at the end of each fermentation cycle, measured as the percentage of viable cells in a population of viable and non-viable cells. Figure legend: white fill (control, no AFA added), gray fill (Ind B, composed of $150 \mathrm{mg} \mathrm{l}^{-1} \mathrm{AF} \mathrm{B}$ and $150 \mathrm{mg} \mathrm{l}^{-1} \mathrm{D} \mathrm{B}$ ), black fill (Ind__Z, composed of $150 \mathrm{mg} \mathrm{l}^{-1} \mathrm{AF}$ Z Z and $150 \mathrm{mg} \mathrm{l}^{-1} \mathrm{D}_{-}^{-} \mathrm{Z}$ ). Values represent the average of triplicate experiments \pm standard deviations

to sulfur metabolism, i.e., S-methylmethionine transport (GO:0015806) and cysteine transport (GO:0042883). In addition, other sulfur assimilation processes like sulfonate dioxygenase activity (GO:0000907) and sulfur compound catabolic process (GO:0044273) were enriched. For Ind Z other GO terms related to sulfur metabolism was enriched among up-regulated genes, including cysteine-and methionine biosynthetic process (GO:0019344/0009086) and sulfate assimilation (GO:0000103). The main up-regulated genes within the mentioned GO terms were $J L P I$ in the Ind $\mathrm{B}$ treatment and MET3 in Ind Z (Fig. 4). JLPI encodes an $\mathrm{Fe}(\mathrm{II})$ dependent sulfonate/alpha-ketoglutarate dioxygenase which has been shown to be induced under sulfur starvation (Zhang et al. 2001) and is believed to make use of aliphatic sulfonates such as taurine, cysteate, and isethionate as alternative sulfur sources (Hogan et al. 1999). MET3 catalyzes the primary step in the intracellular sulfate activation, where sulfate is reduced to sulfide which is involved in cysteine and methionine metabolism (Gierest et al. 1985). Interestingly, both up-regulated genes propose that sulfur starvation is taking place in both treatments, but also that the cells attempt to cope with the stress using different strategies: Ind B-treated cells, by recycling intracellular sulfur and Ind_Z-treated cells by increasing the assimilation of extracellular sulfate. Investigating the significantly overrepresented reporter metabolites within these treatments revealed sulfur-containing compounds as well. For Ind_B, sulfate, S-methylmethionine, taurine, and its degradation product aminoacetaldehyde were seen, in agreement with the JLPI up-regulation. For Ind_Z, only sulfate was significantly overrepresented. Specifically investigating the metabolism of cysteine, methionine and the methionine salvage pathway did not indicate any marked changes in the gene expression controlling these processes. In addition, it was noted that the high-affinity cysteine transporter $Y C T 1$ was strongly up-regulated in Ind_B-treated cells (Kaur and Bachhawat 2007). All in all, both industrial AFA treatments induced sulfur starvation responses, although the effects seemed to be more pronounced in Ind_B.

Beside an up-regulation of sulfate assimilation, the Ind_Z treatment generally contained a larger number of significantly enriched GO terms among up-regulated genes compared to Ind_B, indicating a more diverse and global response caused by the treatment. These $\mathrm{GO}$ terms included plasma membrane organization (GO:0007009), cellular amino acid biosynthetic process (GO:0008652), and response to stress (GO:0006950). One of these stress response genes was the third most upregulated gene in Ind_Z, HSP 12, which encodes a membrane-bound protein involved in maintaining membrane organization (Welker et al. 2010). Other stress-responsive genes were among the most up-regulated genes in Ind $Z$ (> $1.5 \log _{2}$ fold changes) and included HSP30, BTN2, DDR2, OPI10, and CWP2.

Among the down-regulated genes in both Ind B and Ind Z, GO terms were strongly enriched for the biosynthesis of lipids and sterols, in particular ergosterol (GO:0006696). Reporter metabolites revealed an ergosterol intermediate, ergosta-5,7,24(28)-trienol, to be underrepresented in both treatments. Further, the fatty acid synthesis pathway was down-regulated including $A C C 1, F A S 1, F A S 2$, and $O L E 1$, while the elongases $E L O 1, E L O 2$, and $E L O 3$ were largely 

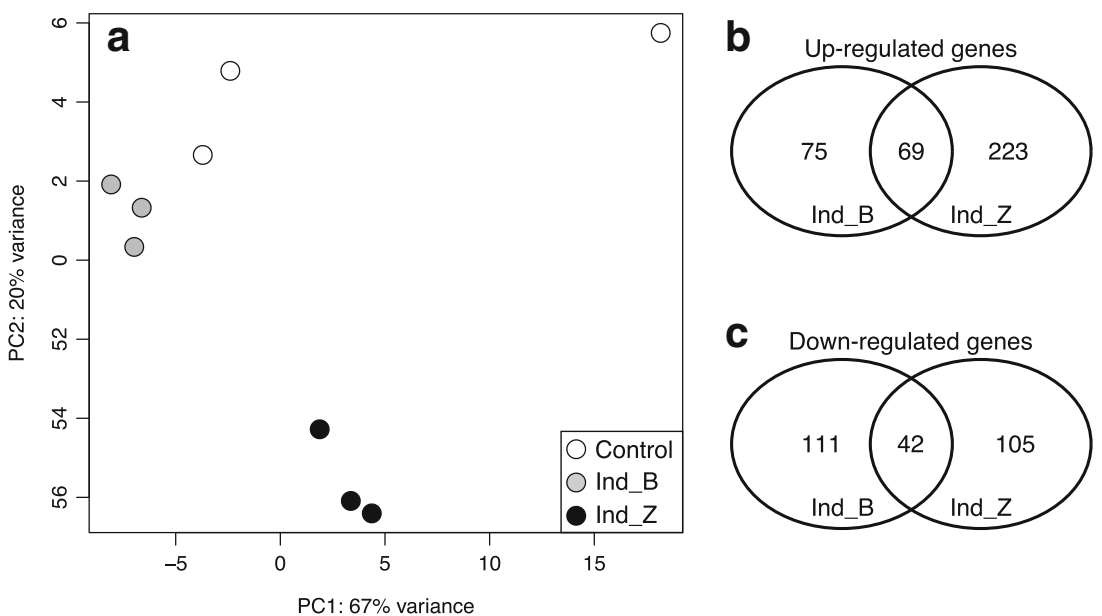

Fig. 3 Overview of transcriptional pertubations caused by the AFA treatments. a Principal component analysis (PCA) of normalized transcript levels in the three replicates of each experimental condition. Samples were collected $4 \mathrm{~h}$ after initiation of the last fermentation cycle. b Significantly differentially expressed up-regulated and c down-

regulated genes caused by the two AFA treatments relative to the control. Figure legend: white fill (control, no AFA added), gray fill (Ind_B, composed of $150 \mathrm{mg} \mathrm{l}^{-1} \mathrm{AF} B \mathrm{~B}$ and $150 \mathrm{mg} \mathrm{l}^{-1} \mathrm{D} \_\mathrm{B}$ ), black fill (Ind_Z, composed of $150 \mathrm{mg} \mathrm{l}^{-1} \overline{\mathrm{AF}} \mathrm{Z}$ and $150 \mathrm{mg} \mathrm{l}^{-1} \overline{\mathrm{D}} \mathrm{Z}$ )

unchanged (Fig. 4). The activation of fatty acids for betaoxidation by FAA4 was also down-regulated in both treatments. Reporter metabolite analysis showed that the lipids, palmitoylCoA in Ind B, and glycerol-3-phosphocholine in Ind Z were underrepresented. Palmitoyl-CoA is a thioester, and hence, its underrepresentation is in agreement with the indications that the cells were experiencing sulfur starvation and that fatty acid synthesis and beta-oxidation were down-regulated.
Further, both treatments showed enrichment of the mitochondrion term (GO:0005739) among down-regulated genes as well as several other mitochondrial processes including mitochondrial inner membrane (GO:0005743), respiratory chain complex IV (GO:0005751), and for Ind_Z, also mitochondrial translation (GO:0032543) and mitochondrial ribosomes (GO:0005762/GO:0005763). We also observed that ferrocytochrome c was underrepresented in both treatments.

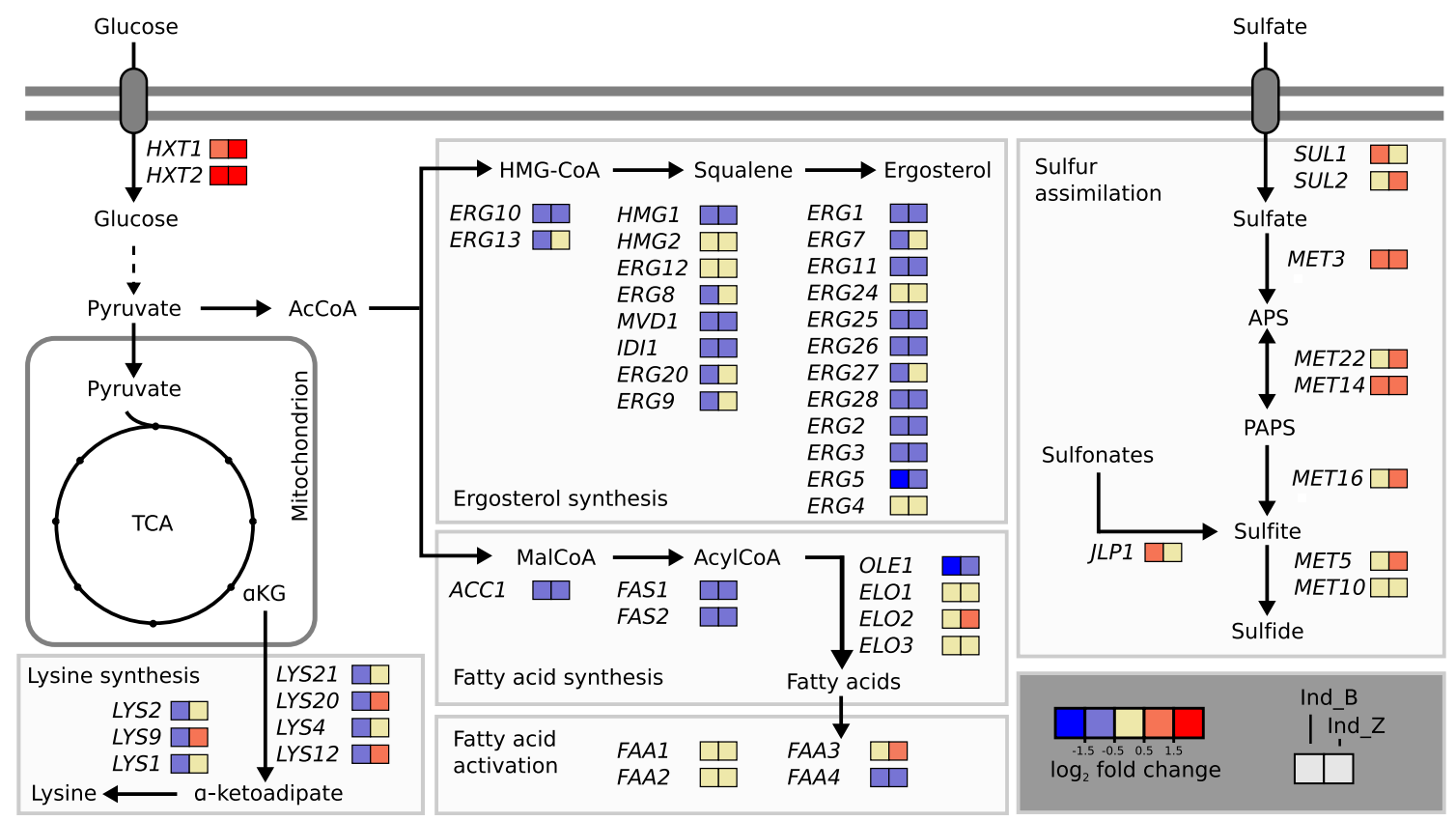

Fig. 4 Schematic representation of the affected parts of yeast metabolism upon exposure to industrial AFA. Color key indicate the transcript fold changes in the AFA-treated cells relative to the control and arrows can represent multiple enzymatic reactions. Samples were collected $4 \mathrm{~h}$ after initiation of the last fermentation cycle 
Although the main transcriptional perturbations were similar in the two industrial treatments, one opposite regulation was seen within cellular amino acid biosynthetic process (GO:0008652). In Ind_B, in particular, branched chain amino acids and lysine biosynthetic genes were down-regulated, while these pathways were unaffected or slightly upregulated in the Ind_Z-treated cells (Fig. 4).

To determine the transcriptional responses to the physiological phenotypes, linear models were constructed to correlate viability and the expression levels of each gene in all replicates of each treatment. We found a total of 245 genes with significant positive correlation and 293 genes with significant inverse correlation to viability $(p<0.01)$, and these gene sets were investigated with an enrichment analysis using GO terms. The most enriched GO terms were seen among the genes with negative correlation to viability, meaning that they were higher expressed in the cultivation with low viability, and included the biosynthetic processes of hydrogen sulfide, cysteine, and methionine, in agreement with the observations in the gene set analysis above. Few GO terms were enriched among the genes with positive correlation to viability and they were related to mitochondrial organization and mitochondrial RNA metabolic processes. This observation agreed with the gene set analysis and confirmed that mitochondrial processes were repressed in the low viability/increased stress AFA treatments.

\section{Discussion}

During microbial fermentations, AFA are commonly added to prevent the detrimental effects of foam formation, such as loss of fermentor space, leading to increased production costs. AFA have previously been shown to alter growth characteristics of microorganisms, but only a limited number of studies have systematically investigated this. Current knowledge on the topic suggests that the biological effects of AFA exposure is highly dependent on AFA composition, organism of choice, and culture conditions (Routledge et al. 2014). Further, it has been shown that different AFA can lead to both increased and reduced growth rates of yeasts (Holmes et al. 2006) and that the yield of recombinant protein in Pichia pastoris and Eschericha coli can be increased upon AFA exposure (Koch et al. 1995; Routledge and Bill 2012). Despite it being documented that AFA can give rise to negative fermentation performance, no studies have investigated the impact of this under industrial relevant conditions or by using genome-wide transcriptional profiling.

In the present work, we have shown that the growth rate of industrial S. cerevisiae strain CAT-1 is reduced upon exposure to AFA that are used in the Brazilian ethanol industry. In microplate fermentations, at $60 \mathrm{mg} \mathrm{l}^{-1}$, corresponding to the average AFA concentration used in industrial settings
(Pecege-Esalq 2012), we observed a 4-6\% reduction in growth rates upon exposure to currently used industrial defoaming treatments (Ind_B and Ind_Z), and the response intensified with increasing concentrations. Microplate fermentations with addition of commercially available AFA, frequently used in the fermentation literature (Antifoam C, Sigma 204, and P2000), resulted in no change in growth rates at concentrations up to $375 \mathrm{mg} \mathrm{l}^{-1}$, approximately ten times the concentration of the industrial AFA tested here. Although the amount of AFA utilized in scientific publications is rarely stated, this correspond to concentration higher than what is commonly used for defoaming purposes in publications where this is explicit (Brochado et al. 2010) as well as the manufacturer's recommendations. These findings suggest that industrially used AFA contain components more harmful to yeasts than what is used in commercially available AFA. One explanation for this might be that industrially used AFA are of varying quality due to efforts to keep production costs down.

To further investigate how the physiological perturbations observed in laboratory fermentations would translate into the industrial ethanol production process, we carried out laboratory simulations of the Brazilian sugarcane-based ethanol production process with recycling of the yeast biomass for $5 \mathrm{cy}$ cles (usually done for 200-230 days in industry, with 2 cycles per day). For these fermentations, we used AFA concentrations of five times the average concentration used in industrial settings, in order to make the effects more pronounced. Since the day to day variation in AFA usage in the industry can change up to tenfold, this can be considered as a plausible exposure level under industrial conditions. The physiological effects of the treatments showed a reduction in viability exerted by both treatments after five fermentation cycles. This led to a decrease in the $\mathrm{CO}_{2}$ evolution which can be used as a proxy for the ethanol production and hence suggests a decrease in ethanol productivity. Since the Brazilian ethanol production process is already extremely efficient with yields as high as $93 \%$ of the theoretical maximum (Amorim et al. 2011) and that more than half of the ethanol final costs are due to the costs of raw materials, any increase in efficiency would result in major economic gains (Della-Bianca et al. 2013). Taken together, the data suggests that industrial AFA is a potential stress factor to yeast cells in sugarcane fermentation, in addition to the commonly reported ones, such as thermal, osmotic and ethanolic stresses (Basso et al. 2008; Amorim et al. 2011; Della-Bianca et al. 2013).

At the transcriptional level, several of the affected cellular processes were seen in both treatments, despite Ind Z giving rise to the most pronounced negative physiological phenotype. Interestingly, both treatments showed indications of sulfur starvation, which is surprising considering the sulfur availability from the sulfuric acid added for lowering the $\mathrm{pH}$ during recycling. Additionally, a down-regulation of mitochondrial processes was observed, which suggests that 
oxygen availability is reduced, as previously shown to be caused by AFA addition to culture medium (Koch et al. 1995). The Ind $Z$ treatment resulted in about half the viability of the control and showed a much more diverse and global transcriptional responses, including a stronger downregulation of mitochondrial processes and an up-regulation of several stress-response genes which were not seen in Ind B.

Lipid metabolism proved to be strongly affected in both treatments, in particular sterol and fatty acid synthesis, which was down-regulated with respect to the control. Previous work has shown that sterol abundance increased in Kluyveromyces bulgaricus and Saccharomyces uvarum under exposure to polyoxyalkylene glycol-oleic acid condensates in aerobic cultivations. The relative composition of sterols was unaffected in S. uvarum, while in K. bulgaricus, there was an increase in ergosterol ratio (Pawiroharsono et al. 1987). The authors further stated that the permeability to certain sugars relevant for molasses fermentation, such as glucose and sucrose, was affected by the presence of the AFA investigated. In the present study, under microaerobic conditions, we saw that the ergosterol biosynthetic pathway was down-regulated while only transcript levels of ERG24 and ERG4 were unchanged (Fig. 4). More recently, it was reported that $S$. cerevisiae grown under ethanol stress had elevated sterol levels while $E R G$ genes were down-regulated (Lahtvee et al. 2016), and emphasizes that the overall sterol content cannot be inferred based on transcript levels alone. Another study showed that oleic acid gets incorporated into phospholipids and glycolipids, and that AFA increased the overall lipid content in the filamentous fungus Aspergillus niger (Nemec and Jernejc 2002). Thus, alterations in lipid biosynthesis may alter membrane fluidity (Lahtvee et al. 2016) and therefore increase sensitivity of yeast cells toward stress factors normally found in molasses-based fermentations (Della-Bianca et al. 2013).

Taken together, the observed reduction in growth rate and cell viability, as well as increased stress responses, could be explained by several factors. The repression of sterol metabolism suggests a change in sterol composition, likely as a response to an increased membrane permeability as previously reported for yeast upon AFA exposure (Pawiroharsono et al. 1987). In inhibitor-rich medium such as molasses (DellaBianca et al. 2013), this increased permeability could be contributing to the reduced growth rate since the cells attempt to cope with inhibitors by inducing stress responses, e.g., to maintain membrane organization as seen in the up-regulation of HSP 12 in this study. This requires an increased ATP demand which is then diverted away from growth processes. In turn, failing to efficiently remove inhibitors might contribute to the observed decrease in viability as well. Another factor is the oxygen transfer rate in the medium, which can be significantly increased or reduced upon AFA addition (Morao et al. 1999; Routledge et al. 2011). The observed down-regulation of mitochondrial processes suggests a reduction in oxygen availability and this could contribute to a reduced ATP generation via oxidative phosphorylation and hence hamper growth. In particular, since the scale-down molasses fermentations conducted in this study took place under microaerobic conditions, changes in dissolved oxygen concentrations due to the presence of AFA might have drastic effects on cell physiology.

Overall, this study has documented distinct negative effects associated with the use of industrial AFA currently used in the Brazilian ethanol fermentation industry. The perturbations were documented at physiological and transcriptional levels. Our results suggest that the decreased viability and induction of stress responses is strongly related to changes in lipid metabolism. These findings highlight the importance in developing less harmful defoaming strategies in industrial fermentations, in order to prevent compromising cellular performance of the production organism.

Acknowledgements The authors would like to thank Dr. Tammy Doty for extraction of total RNA and Camila do Nascimento and João Rodenbusch Destro for their helpful support in carrying out HPLC analysis and assistance in cultivation experiments. This study was funded by Novozymes Latin America Ltda. (Araucária, Brazil) and Fundação de Amparo à Pesquisa do Estado de São Paulo (FAPESP) (grant number 2016/10240-7). We are also grateful to Victor Guadalupe Medina, Vijay Raghavendran, Viviane Müller and Daniel Cardinali for carefully reading this manuscript and giving valuable comments.

\section{Compliance with ethical standards}

Conflict of interest The authors declare that they have no conflict of interest.

Ethical approval This article does not contain any studies with human participants or animals performed by any of the authors.

\section{References}

Amorim HV, Lopes ML, de Castro Oliveira JV, Buckeridge MS, Goldman GH (2011) Scientific challenges of bioethanol production in Brazil. Appl Microbiol Biotechnol 91:1267-1275. https://doi.org/ 10.1007/s00253-011-3437-6

Anders S, Pyl PT, Huber W (2015) HTSeq — a Python framework to work with high-throughput sequencing data. Bioinformatics 31:166-169. https://doi.org/10.1093/bioinformatics/btu638

Andrews S (2012) FastQC a quality control tool for high throughput sequence data. http://www.bioinformatics.babraham.ac.uk/projects/ fastqc. Accessed 6 Sep 2017

Aung HW, Henry SA, Walker LP (2013) Revising the representation of fatty acid, glycerolipid, and glycerophospholipid metabolism in the consensus model of yeast metabolism. Ind Biotechnol 9:215-228. https://doi.org/10.1089/ind.2013.0013

Babrzadeh F, Jalili R, Wang C, Shokralla S, Pierce S, RobinsonMosher A, Nyren P, Shafer RW, Basso LC, de Amorim HV, de Oliveira AJ, Davis RW, Ronaghi M, Gharizadeh B, Stambuk BU (2012) Whole-genome sequencing of the efficient industrial fuel-ethanol fermentative Saccharomyces 
cerevisiae strain CAT-1. Mol Gen Genomics 287:485-494. https://doi.org/10.1007/s00438-012-0695-7

Basso LC, de Amorim HV, de Oliveira AJ, Lopes ML (2008) Yeast selection for fuel ethanol production in Brazil. FEMS Yeast Res 8: 1155-1163. https://doi.org/10.1111/j.1567-1364.2008.00428.x

Basso TO, de Kok S, Dario M, do Espirito-Santo JCA, Müller G, Schlölg PS, Silva CP, Tonso A, Daran J-M, Gombert AK, van Maris AJA, Pronk JT, Stambuk BU (2011) Engineering topology and kinetics of sucrose metabolism in Saccharomyces cerevisiae for improved ethanol yield. Metab Eng 13:694-703. https://doi.org/10.1016/j. ymben.2011.09.005

Basso TO, Gomes FS, Lopes ML, de Amorim HV, Eggleston G, Basso LC (2014) Homo- and heterofermentative lactobacilli differently affect sugarcane-based fuel ethanol fermentation. Antonie Van Leeuwenhoek 105:169-177. https://doi.org/10.1007/s10482-0130063-6

Blasco L, Viñas M, Villa TG (2011) Proteins influencing foam formation in wine and beer: the role of yeast. Int Microbiol 14:61-71. https:// doi.org/10.2436/IM.V14I2.54426

Brochado AR, Matos C, Møller BL, Hansen J, Mortensen UH, Patil KR (2010) Improved vanillin production in baker's yeast through in silico design. Microb Cell Factories. https://doi.org/10.1186/14752859-9-84

Carbon S, Ireland A, Mungall CJ, Shu S, Marshall B, Lewis S, the AmiGO Hub, the Web Presence Working Group (2009) AmiGO: online access to ontology and annotation data. Bioinformatics 25: 288-289. https://doi.org/10.1093/bioinformatics/btn615

Della-Bianca E, Basso TO, Stambuk BU, Basso LC, Gombert AK (2013) What do we know about the yeast strains from the Brazilian fuel ethanol industry? Appl Microbiol Biotechnol 97:979-991. https:// doi.org/10.1007/s00253-012-4631-x

Eisner MD, Jeelani SAK, Bernhard L, Windhab EJ (2007) Stability of foams containing proteins, fat particles and nonionic surfactants. Chem Eng Sci 62:1974-1987. https://doi.org/10.1016/j.ces.2006. 12.056

Engel SR, Dietrich FS, Fisk DG, Binkley G, Balakrishnan R, Costanzo MC, Dwight SS, Hitz BC, Karra K, Nash RS, Weng S, Wong ED, Lloyd P, Skrzypek MS, Miyasato SR, Simison M, Cherry JM (2014) The reference genome sequence of Saccharomyces cerevisiae: then and now. G3 4:389-398. https://doi.org/10.1534/g3.113.008995

Garcia-Ochoa F, Gomez E (2009) Bioreactor scale-up and oxygen transfer rate in microbial processes: an overview. Biotechnol Adv 27: 153-176. https://doi.org/10.1016/j.biotechadv.2008.10.006

Gierest H, Thao NN, Surdin-Kerjan Y (1985) Transcriptional regulation of the MET3 gene of Saccharomyces cerevisiae. Gene 34:269-281. https://doi.org/10.1016/0378-1119(85)90136-2

Grosz R, Stephanopoulos G (1990) Physiological, biochemical, and mathematical studies of micro-aerobic continuous ethanol fermentation by Saccharomyces cerevisiae. I: hysteresis, oscillations, and maximum specific ethanol productivities in chemostat culture. Biotechnol Bioeng 36:1006-1019. https://doi.org/10.1002/bit. 260361006

Hogan DA, Auchtung TA, Hausinger RP (1999) Cloning and characterization of a sulfonate/ $\alpha$-ketoglutarate dioxygenase from Saccharomyces cerevisiae. J Bacteriol 181:5876-5879

Holmes W, Smith R, Bill R (2006) Evaluation of antifoams in the expression of a recombinant FC fusion protein in shake flask cultures of Saccharomyces cerevisiae. Microb Cell Factories 5:P30. https://doi. org/10.1186/1475-2859-5-S1-P30

Junker B (2007) Foam and its mitigation in fermentation systems. Biotechnol Prog 23:767-784. https://doi.org/10.1021/bp070032r

Kaur J, Bachhawat AK (2007) Yctlp, a novel, high-affinity, cysteinespecific transporter from the yeast Saccharomyces cerevisiae. Genetics 176:877-890. https://doi.org/10.1534/genetics.107. 070342
Kim D, Pertea G, Trapnell C, Pimentel H, Kelley R, Salzberg SL (2013) TopHat2: accurate alignment of transcriptomes in the presence of insertions, deletions and gene fusions. Genome Biol 14:R36. https:// doi.org/10.1186/gb-2013-14-4-r36

Koch V, Riiffer H, Schiigerl K, Innertsberger E, Menzel H, Weis J (1995) Effect of antifoam agents on the medium and microbial cell properties and process performance in small and large reactors. Process Biochem 30:435-446

Lahtvee P-J, Kumar R, Hallstrom BM, Nielsen J (2016) Adaptation to different types of stress converge on mitochondrial metabolism. Mol Biol Cell 27:2505-2514. https://doi.org/10.1091/mbc.E16-03-0187

Love MI, Huber W, Anders S, Lönnstedt I, Speed T, Robinson M, Smyth G, McCarthy D, Chen Y, Smyth G, Anders S, Huber W, Zhou Y-H, Xia K, Wright F, Wu H, Wang C, Wu Z, Hardcastle T, Kelly K, Van De Wiel M, Leday G, Pardo L, Rue H, Van Der Vaart A, Van Wieringen W, Boer J, Huber W, Sültmann H, Wilmer F, von Heydebreck A, Haas S, Korn B, Gunawan B, Vente A, Füzesi L, Vingron M, Poustka A, Gentleman R, Carey V, Bates D, Bolstad B, Dettling M, Dudoit S, Ellis B, Gautier L, Ge Y, Gentry J, Hornik K, Hothorn T, Huber W, Iacus S, Irizarry R, Leisch F, Li C, Maechler M, Rossini A, Sawitzki G, Smith C, Smyth G, Tierney L, Yang J, Zhang J, McCullagh P, Nelder J, Hansen K, Irizarry R, Wu Z, Risso D, Schwartz K, Sherlock G, Dudoit S, Smyth G, Bottomly D, Walter N, Hunter J, Darakjian P, Kawane S, Buck K, Searles R, Mooney M, McWeeney S, Hitzemann R, Pickrell J, Marioni J, Pai A, Degner J, Engelhardt B, Nkadori E, Veyrieras J-B, Stephens M, Gilad Y, Pritchard J, Hastie T, Tibshirani R, Friedman J, Bi Y, Davuluri R, Feng J, Meyer C, Wang Q, Liu J, Liu X, Zhang Y, Benjamini Y, Hochberg Y, Bourgon R, Gentleman R, Huber W, McCarthy D, Smyth G, Li J, Tibshirani R, Cook R, Hammer P, Banck M, Amberg R, Wang C, Petznick G, Luo S, Khrebtukova I, Schroth G, Beyerlein P, Beutler A, Frazee A, Langmead B, Leek J, Trapnell C, Hendrickson D, Sauvageau M, Goff L, Rinn J, Pachter L, Glaus P, Honkela A, Rattray M, Anders S, Reyes A, Huber W, Sammeth M, Robinson M, McCarthy D, Smyth G, Zhou X, Lindsay H, Robinson M, Leng N, Dawson J, Thomson J, Ruotti V, Rissman A, Smits B, Haag J, Gould M, Stewart R, Kendziorski C, Law C, Chen Y, Shi W, Smyth G, Hubert L, Arabie P, Witten D, Irizarry R, Wu Z, Jaffee H, Asangani I, Dommeti V, Wang X, Malik R, Cieslik M, Yang R, Escara-Wilke J, Wilder-Romans K, Dhanireddy S, Engelke C, Iyer M, Jing X, Wu Y-M, Cao X, Qin Z, Wang S, Feng F, Chinnaiyan A, Ross-Innes C, Stark R, Teschendorff A, Holmes K, Ali H, Dunning M, Brown G, Gojis O, Ellis I, Green A, Ali S, Chin S-F, Palmieri C, Caldas C, Carroll J, Robinson D, Chen W, Storey J, Gresham D, McMurdie P, Holmes S, Vasquez J, Hon C, Vanselow J, Schlosser A, Siegel T, Zhou Y, Zhu S, Cai C, Yuan P, Li C, Huang Y, Wei W, Cox D, Reid N, Robinson M, Smyth G, Pawitan Y, Armijo L, Di Y, Schafer D, Cumbie J, Chang J, Abramowitz M, Stegun I, Newton M, Kendziorski C, Richmond C, Blattner F, Tsui K, Huber W, von Heydebreck A, Sultmann H, Poustka A, Vingron M, Durbin B, Hardin J, Hawkins D, Rocke D, Friedman J, Hastie T, Tibshirani R, Cule E, Vineis P, De Iorio M, Cook R, Weisberg S, Lawrence M, Huber W, Pagès H, Aboyoun P, Carlson M, Gentleman R, Morgan M, Carey V, Anders S, Pyl P, Huber W, Delhomme N, Padioleau I, Furlong E, Steinmetz L, Liao Y, Smyth G, Shi W, Kim D, Pertea G, Trapnell C, Pimentel H, Kelley R, Salzberg S (2014) Moderated estimation of fold change and dispersion for RNA-seq data with DESeq2. Genome Biol 15: 550. https://doi.org/10.1186/s13059-014-0550-8

Morao A, Maia CI, Fonseca MMR, Vasconcelos JMT, Alves SS (1999) Effect of antifoam addition on gas-liquid mass transfer in stirred fermenters. Bioprocess Eng 20:165-172

Nemec T, Jernejc K (2002) Influence of Tween 80 on lipid metabolism of an Aspergillus niger strain. Appl Biochem Biotechnol 101:229-238. https://doi.org/10.1385/ABAB:101:3:229 
Patil KR, Nielsen J (2005) Uncovering transcriptional regulation of metabolism by using metabolic network topology. Proc Natl Acad Sci U S A 102:2685-2689. https://doi.org/10.1073/pnas.0406811102

Pawiroharsono S, Naji B, Bonaly R, Tonetti F, Chasseboeuf C, Richter JP (1987) Permeability and membrane sterol distribution in Saccharomyces uvarum and Kluyveromyces bulgaricus grown in presence of polyoxyalkylene glycol-oleic acid condensates. Appl Microbiol Biotechnol 27:181-185. https://doi.org/10.1007/ BF00251942

Pecege-Esalq (2012) Custos de producao de cana-de-acucar, acucar e etanol no Brasil: acompanhamento da Safra 2011/2012 - Centrosul http://canaldoprodutorcombr/sites/default/files/relatorio_ Custos_Prod_Cana_2011_12pdf Accessed 6 Sep 2017

Prins A, Van Riet K (1987) Proteins and surface effects in fermentation: foam antifoam and mass transfer. Trends Biotechnol 5:296-301

Raghavendran V, Basso TP, da Silva JB, Basso LC, Gombert AK (2017) A simple scaled down system to mimic the industrial production of first generation fuel ethanol in Brazil. Antonie Van Leeuwenhoek 110:971-983. https://doi.org/10.1007/s10482-017-0868-9

Renewable Fuels Association (2016) Fueling a high octane future. https:// wwwethanolrfaorg/wp-content/uploads/2016/02/Ethanol-IndustryOutlook-2016pdf. Accessed 6 Sep 2017

Routledge SJ, Bill RM (2012) The effect of antifoam addition on protein production yields. In: Bill RM (ed) Recombinant Protein Production in Yeast. Springer, Totowa, pp 87-97

Routledge SJ, Hewitt CJ, Bora N, Bill RM (2011) Antifoam addition to shake flask cultures of recombinant Pichia pastoris increases yield. Microb Cell Factories. https://doi.org/10.1186/1475-2859-10-17

Routledge SJ, Poyner DR, Bill RM (2014) Antifoams: the overlooked additive? Pharm Bioprocess 2:103-106
Varemo L, Nielsen J, Nookaew I (2013) Enriching the gene set analysis of genome-wide data by incorporating directionality of gene expression and combining statistical hypotheses and methods. Nucleic Acids Res 41:4378-4391. https://doi.org/10.1093/nar/gkt111

Vidyarthi AS, Desrosiers M, Tyagi RD, Valéro JR (2000) Foam control in biopesticide production from sewage sludge. J Ind Microbiol Biotechnol 25:86-92. https://doi.org/10.1038/sj.jim.7000038

Walker GM (2010) Bioethanol: science and technology of fuel alcohol. Ventus Publishing ApS, Frederiksberg

Welker S, Rudolph B, Frenzel E, Hagn F, Liebisch G, Schmitz G, Scheuring J, Kerth A, Blume A, Weinkauf S, Haslbeck M, Kessler H, Buchner J (2010) Hsp12 is an intrinsically unstructured stress protein that folds upon membrane association and modulates membrane function. Mol Cell 39:507-520. https://doi.org/10.1016/j. molcel.2010.08.001

Yates A, Akanni W, Amode MR, Barrell D, Billis K, Carvalho-Silva D, Cummins C, Clapham P, Fitzgerald S, Gil L, Girón CG, Gordon L, Hourlier T, Hunt SE, Janacek SH, Johnson N, Juettemann T, Keenan S, Lavidas I, Martin FJ, Maurel T, McLaren W, Murphy DN, Nag R, Nuhn M, Parker A, Patricio M, Pignatelli M, Rahtz M, Riat HS, Sheppard D, Taylor K, Thormann A, Vullo A, Wilder SP, Zadissa A, Birney E, Harrow J, Muffato M, Perry E, Ruffier M, Spudich G, Trevanion SJ, Cunningham F, Aken BL, Zerbino DR, Flicek P (2016) Ensembl 2016. Nucleic Acids Res 44:D710-D716. https:// doi.org/10.1093/nar/gkv1157

Zhang N, Merlotti C, Wu J, Ismail T, El-Moghazy A-N, Ahmed Khan S, Butt A, Gardner DCJ, Sims PFG, Oliver SG (2001) Functional analysis of six novel ORFs on the left arm of chromosome XII of Saccharomyces cerevisiae reveals three of them responding to Sstarvation. Yeast 18:325-334. https://doi.org/10.1002/10970061(20010315)18:4<325::AID-YEA669>3.0.CO;2-K 